\title{
Supporting Each Other - The Calderdale Memory Group
}

\author{
Victoria Carek ${ }^{1}$
}

South West Yorkshire Mental Health NHS Trust 


\section{Supporting each other: The Calderdale Memory Group}

Victoria Carek

\section{Abstract}

The Calderdale Memory Group is a time-limited support, information and activity group for people affected by a diagnosis of early-stage dementia.

This paper will discuss the development of the Calderdale Memory Group in the context of local and wider dementia care service provision. The role of such nonpharmacological interventions is discussed in relation to the literature, and with reference to Tom Kitwood's (1997) 'new culture' of dementia care.

There have been many attempts to cater to the needs of patients and caregivers. Historically their needs have been treated separately. This paper proposes that in early-stage dementia support, education and the maintenance and strengthening of relationships are vital. Additionally this paper outlines the ongoing qualitative evaluation of the group.

Key words: Memory Groups, Peer support, Early-stage Dementia, Psychosocial

\section{Introduction}

An increasing awareness of dementia, leading to earlier diagnosis, has resulted in a client group of increasing size with complex psychosocial needs.

Around 750,000 people in the UK are currently diagnosed with dementia, with this figure set to rise by up to 100,000 by 2010 according to the Alzheimer's Society (2005).

Dementia is difficult to define. It is a syndrome with decline from previous normal functioning; it affects several areas of cortical function and is progressive in nature. The cause, cortical areas affected and rate of progression are found in numerous combinations. Dementia of Alzheimer's type (55\%), Vascular dementia (20\%) and Dementia with Lewy Bodies (15\%) are the three most common causes (Alzheimer's Society, 2005).

Pharmaceutical treatments for early-stage dementia have been found to have some effect in slowing this degenerative condition and drug treatments are also available for many of the secondary symptoms (Royal College of Psychiatrists, 2005). While medication may provide alleviation of symptoms they are not a cure. There are numerous potential side effects and contraindications that can prevent or discontinue prescription of such medications (Royal College of Psychiatrists, 2005). So, while many see hope in pharmaceutical treatments, it is a fragile hope, and not available to all.

A medical focus on a person's neurology and stage of disease overlooks the significant psychosocial impact that dementia has on both patients and caregivers. The medical view alone does not form an adequate base from which to work with the day-to-day challenges of dementia (Perrin \& May, 2000). It is important to remember that alongside the onset of dementia a whole range of social and environmental influences will contribute to a person's current situation. In light of this it would seem sensible to consider how we can better serve the psychosocial needs of those affected by a diagnosis of early-stage dementia, both patients and caregivers. 
Kitwood (1997) was integral to what has often been termed the 'new culture' of dementia care. Kitwood proposed that psychological states are inextricably linked to brain states and that it is unhelpful to think of dementia as a linear process. He emphasised that 'malignant' social psychological events or states may be an exacerbating factor in dementia, for example, disempowerment, labelling and infantilisation. He noted that this could be reversed in a process he named 'rementia', where the event or state is changed, and that this can reduce any additional or exacerbated presentation.

Further, Kitwood (1997) described a cluster of needs of the person with dementia that include attachment, comfort, identity, occupation and inclusion. These needs overlap and come together to contribute to the central need for love (an unconditional love that makes a place safe, standing by a person no matter what the situation or level of confusion). Kitwood proposed that the fulfillment of one of these needs contributes towards fulfillment of the others as they are closely linked. Targeting these needs can be a route to wellbeing and reducing exacerbated presentation.

A psychiatric label such as dementia significantly impacts upon a person's psychosocial wellbeing, and can contribute toward a 'malignant' social psychology (Kitwood, 1997). Feelings of loneliness, embarrassment, rejection, confusion and frustration may be experienced. The initial period following diagnosis requires important management of emotions (grief, denial, anger, upset), practical information and preparation. People with dementia are likely to '...inhabit a shrinking social world...' (Kitwood, 1997) which is often commenced prior to diagnosis as symptoms first develop. It is also important to remember that other members of a patient's social network are also trying to adapt to a life-disrupting problem.

\section{The role of others}

Other people with dementia are a vital source of support to someone with the same diagnosis, as are partners or relatives in the same situation. They are the only people who truly know what the experience is like.

Peer support is a well-used term with various definitions. Commonly it is determined to be a form of social and emotional support with mutual giving and receiving of this support implied. Meed, Hilton and Curtis (2001) offer that peer support is '...founded on key principles of respect, shared responsibility, and a mutual agreement of what is helpful'. Peer support can be thought of as a system of social sharing, gaining empathy and assistance from others in a similar situation, with all members having some level of experiential knowledge.

Solomon (2004) draws on social learning theory in outlining the function of peer support, noting the credibility of peers as role models due to their ongoing or prior involvement with mental health services. Solomon suggests interaction with peers who demonstrate successful coping strategies is likely to influence positive behaviour change in others.

Additional benefits of peer support have been conceptualised with the help of social comparison theory. 'By interacting with others who are perceived to be better than them, peers are given a sense of optimism and something to strive toward...an incentive... offers hope... downward comparison to those who seem so much worse off than themselves puts in perspective how bad things could be....' (Solomon, 2004, p4, citing Salzer et al, 2002). In this context social comparison is relevant to the modelling of various coping strategies within the group, seeing room for improvement (upward comparison) while feeling they are coping better than others in some areas (downward comparison). As dementia is progressive, continued acceptance and adjustment to continuing changes is needed. 
'Mutual support groups have been found to enhance quality of life, improve self esteem, provide valued roles and enhance supportive social networks....' (Davidson, Chinman, Moos, Weingarten, Staynes \& Tobos, 1999, p3). They rely on the experiential knowledge of the members, drawing on their insight of living through, or with, the illness or disorder. Members gain new information through exposure to differing perspectives and successful role models, which can enhance their own coping and problem solving skills (Kaufman, Freund, Wilson, 1989).

\section{Support Groups for people with early-stage dementia}

The initial conceptualisation and development of support groups for people newly diagnosed with early stage dementia can be credited to Robyn Yale. Yale's (1995a) work has been instrumental in making the transition from aiming literature and support services at the caregiver to the realisation that many people with early-stage dementia are 'willing and able to share their feelings, concerns and experiences when given the opportunity'.

Yale (1995b) focuses on the abilities, skills and strengths of people with dementia. 'It is important to acknowledge that people with dementia have abilities that need maximising so they can remain active participants in life' (Alzheimer's Society International, 2005).

Marshall (2003) described a support group for early stage dementia when promoting the benefit of meeting people in a similar situation, who are dealing with similar difficulties. Peer support is extremely valuable as sharing experiences and gaining a greater understanding of living with dementia helps to reduce stigma. Fears and worries can be shared openly, any embarrassment is reduced via the realisation that they are not alone, and coping strategies can be exchanged.

Marshall $(1999 ; 2001)$ evaluated group therapy with older adults who had functional problems or early dementia, and found that meeting others with the same problem was stated as the most helpful aspect of the groups. Marshall (2003) discussed the importance of peer support in gaining a balance between denial of the diagnosis of dementia and being overwhelmed by it.

Groups have the potential to aid in the identification and expression of emotions, an important element of wellbeing. Groups offer an opportunity to share thoughts and experiences with peers who have knowledge unique to those in a similar situation. Emotional experiences will be confounded by denial, self-blame and catastrophic thinking. The support of others who understand these experiences first hand is key to an acknowledgement and acceptance of the situation and regaining a sense of control. Having an opportunity to converse with other people affected by a diagnosis of early-stage dementia in a safe environment also illustrates how varied people's experiences can be.

Nolan, Gordon and Keady (1996) emphasise the importance of family care, acknowledging both the burdens and satisfactions experienced. Families vary in composition, beliefs, personality and so on. The reasons for choosing to, or not choosing to, care for a family member will vary considerably. It is important to be aware of the pressure on relatives; this may be from various sources including their own conscience, other family members, religious beliefs, past promises or the local community. When a family member receives a diagnosis both they and their family and friends experience grief emotions. This process of anticipatory grief may last several years (Nolan et al, 1996). 
An important aspect of support services is how they are described and presented to the potential users. There are several underlying connotations of support services of any nature; these may include a loss of normality, a sense of failure or feeling they have abandoned their duty (Nolan, Gordon and Keady, 1996).

It is vital to consider both the client and caregiver and how they view services. There is a reciprocal triadic relationship between the service, the person with dementia and the caregiver. It is important to consider what each takes from and gives to the other. It is all too easy to generalise. However, acknowledging the complexities of each individual situation is key to service interventions being useful. It is essential to be able to adapt activities and information to take account of each person's preferences, needs, interests and abilities.

\section{Wellbeing and reducing the presentation of excess impairment}

Psychosocial wellbeing has been outlined by the Bradford Dementia Group (in Perrin \& May, 2000). They note several indicators of wellbeing, including warmth and affection, initiating social contact, being purposeful, bodily relaxation, self-respect, making wishes known and humour.

A person's wellbeing can impact upon the presentation of their current difficulties. Both physical factors (such as tiredness) and psychological factors (such as anxiety) affect concentration (Harris, cited in Robinson, 2003). When a client notices that they are forgetful, they may begin to have negative thoughts about this (fear, shame). They may begin to feel 'bad' (low, negative outlook), and this in turn can lead to further poor concentration and the person being less likely to remember things in the future- activation of a vicious cycle of forgetfulness (Harris, cited in Robinson, 2003).

Additionally Clare (1999) noted that due to the level of insight present in early-stage dementia, clients often experience feelings of shame and embarrassment that can again lead to further negative thoughts and feelings (psychological factors), which may fuel the cycle of forgetfulness.

Yale (1995a) similarly noted that the cognitive impairment in dementia is exacerbated by poor mental health causing 'excess disability'. Yale suggests from anecdotal evidence that stimulation, socialisation, and support can improve mood and maximise the cognitive functioning of people with early-stage dementia (Yale 1995b). Yale promotes the role of support groups in enhancing a sense of wellbeing and belonging at a time when many other life-long roles are being lost. After diagnosis it is common for many tasks to be abandoned completely when they are still achievable; partners can become overprotective and take over many roles. A balance is required between denial and being overwhelmed by the diagnosis.

\section{Local Service Context}

Both the developments in pharmaceutical treatments for dementia and increased media coverage have led to more people with memory difficulties presenting to their general practitioner, anxious about a possible diagnosis of dementia. Locally this has produced an increase in the referral rates to older adult psychology and to the Dementia Advice and Support Services (DASS) provided by Calderdale Age Concern. In 2001 a specialist Memory Assessment and Therapy Service (MATs) was established in Calderdale. This is a multidisciplinary team taking referrals for assessment, diagnosis and then signposting to appropriate services. The service has never reached the staffing levels required yet demands on the service have continued to increase. Assessments within the service are taken from a medical, cognitive, functional and 
carer perspective. Diagnoses are then made within a supportive environment. Community Psychiatric nurses from the MATs team monitor those prescribed the dementia drug treatments (acetylcholinesterase inhibitors). Those diagnosed with dementia but not prescribed are referred to the Community Mental Health Team and any other appropriate services.

Since MATs was formed in November 2002 there have been approximately 300 patients prescribed the dementia drugs following assessment. They remain on the team's caseload for as long as their prescription continues. This caseload continues to grow, with 167 direct referrals to the MATs team in the last twelve months. A further 48 patients also receive ongoing MATs monitoring following diagnosis of dementia and prescription at outpatients clinic (Oct 2004 to May 2005).

There is an awareness of gaps in the services provided to this growing client group. Both MATs workers and the CMHT conduct the assessment, diagnosis and monitoring in a supportive manner. However, from diagnosis there may be a range of psychosocial issues which are not catered for, including acknowledging and acceptance of the diagnosis, adjustment to this, emotional reactions associated, an opportunity to seek information, voice fears and so on. This highlights a significant service gap evident locally.

When a person is diagnosed with dementia, particularly those in the early stages, they may not feel that day care services are appropriate. Their partner, relative or friend may not relate to the term 'carer' as this is not their current role and so do not feel ready to attend carer groups. Those who are diagnosed with dementia but do not feel ready to access existing services (e.g. day care) return home with a label for the difficulties they are experiencing and only those prescribed retain some regular contact from the MATs team.

Information and education relating to a diagnosis of dementia, its implications, and preparing for the future, are typically provided for relatives rather than the person with dementia (Bender \& Constance, 2005). Failing to provide support and information for those who receive the diagnosis creates disempowerment (Kitwood, 1997). Taking a role away from the person with dementia and handing it to the 'carer' (who may then be more informed about dementia than the person diagnosed) can create an early disparity in their relationship.

\section{Outline of the Calderdale Memory Group}

The Memory Group in Calderdale began in 2002. A steering group of interested parties from psychology services, Savile Close day services, Age Concern Calderdale and Dementia Advice and Support Service (DASS, a part of Age Concern) was formed to discuss the gaps in local service provision for those with early-stage dementia and to act upon this.

The initial conceptualisation was to provide a service for both the person with a diagnosis of early-stage dementia and their chosen guest. Time was spent gathering information, including a literature review and consideration of both local developments and best practice nationally. A single group for both client and guest was considered to be appropriate. The group would be semi-structured with content largely determined by member needs and requests. It would offer an opportunity to meet others in a similar situation to share experiential information. The group was proposed to provide a supportive environment for new learning, gaining information, sharing of coping strategies and experiences. The overall aims were to increase psychosocial wellbeing through socialisation, self-esteem, activities, and to strengthen or maintain relationships.

Time-limited groups were planned with a duration of eight weeks (since increased to ten following member feedback). The referral criteria required the person diagnosed 
to have an awareness of this diagnosis, a desire for social contact and support, a need or willingness to attend with a guest to build upon the relationship, and to be likely benefit from the group aims.

The groups were run weekly for two hours with 2-4 facilitators and 6-12 members, located in a community venue. Each person with dementia referred was encouraged to bring a guest of his or her choice (partner, relative, neighbour).

The first group started in January 2003. Since then a total of five have been run with 39 members having completed the course. During this time only four people decided not to attend for the duration of the group. Following the third time-limited group member feedback initiated the creation of an Ongoing Memory Group, which runs fortnightly for two hours with 2-3 facilitators present. All members who have completed a time-limited group are invited to attend and meet with other past members. This group allows a continuation of socialisation, support and a link to services. This link to services has been reported by members as extremely reassuring and has allowed many queries to be resolved without accessing additional service routes.

The Calderdale Memory Group has three central components -support, activity and information. Support is available from the other members of the group, the facilitators, and any additional services as appropriate. Social resources are essential in the management of stress and coping (Nolan, Grant and Ellis, 1990). The group provides a supportive safe environment and offers access to both professional and peer advice and support.

Activity within the group is important; it can act as a means of normalising a situation, allowing people to broach more sensitive topics within the safety of a structured activity. For example, the Calderdale Memory Group has completed a large-scale collage using material pieces pushed into a polystyrene block with a pencil. This activity was simple and allowed everyone to contribute and work as a larger group while perhaps conversing in smaller groups. Other activities in the group have included reminiscence, crafts, quizzes, and sharing hobbies or skills (e.g., one member playing the organ for a sing along and doing requests).

The role of information and education within the group serves to allow questions and fears to be raised, offering an opportunity to gain factual knowledge. There was frequent debate between the facilitators about information sharing in the group regarding the progression of dementia. At times there were concerns about offering factual information without creating fear and panic. However, if every loss and change in the person with dementia is a shock, then the patient, family and friends will be forced to experience repeated grief reactions (Nolan, Gordon and Keady, 1996).

The Calderdale Memory Group provides an opportunity for members to attempt to break the vicious cycle of forgetfulness (Harris, in Robinson 2003) outlined earlier, via empowerment, support, and increasing self-esteem. In doing so confounding psychological factors should be reduced and a presentation of increased impairment avoided. 'You don't want to appear worse than you are, you want to appear as strong as you can be' (Client comment, Alzheimer's Association Fact sheet).

The Calderdale Memory Group model (Figure 1) illustrates the interaction of relationships/social contact, support, activity and information. This model shows a triadic relationship between the person with dementia, their guest and the facilitators. The model emphasizes relationships/social contact and support as central. The group offers both peer support and a link to wider services. This model is suggested as a potential route to wellbeing and from this a means of avoiding a presentation of excess impairment (Yale, 1995a). 


\section{Figure 1. The Calderdale Memory Group model}

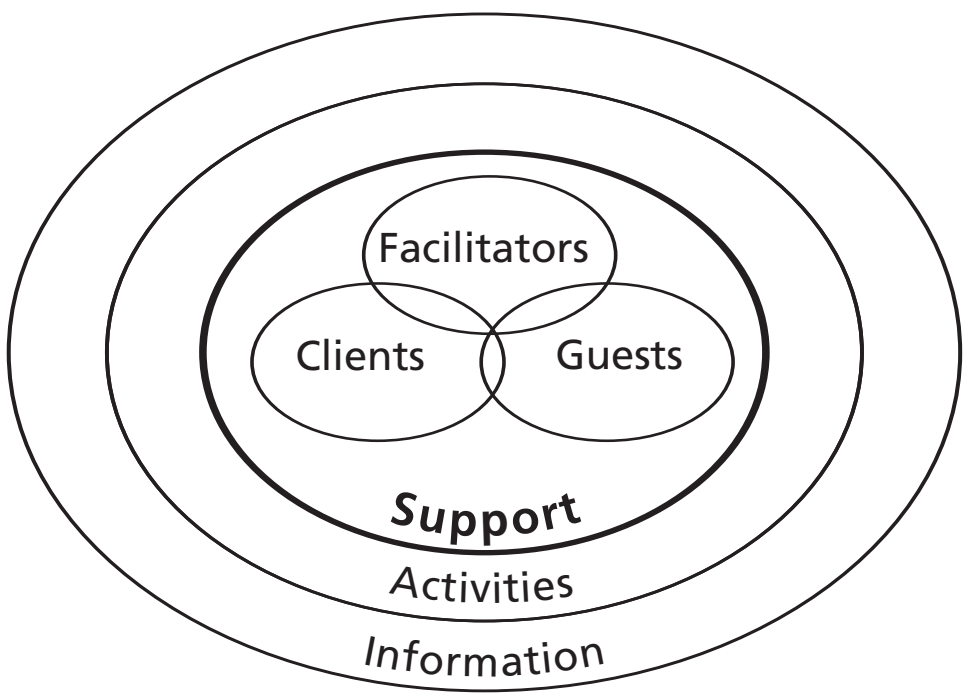

\section{Evaluation of the Calderdale Memory Group}

Evaluation was built into the group from its onset. Because of the self-steering, supportive nature of the group it was felt that evaluation had to be of an informal nature, ensuring the dynamics of the group would not be significantly impacted upon. Qualitative information was collected using opened ended questions. Both written and verbal feedback was collected allowing respect for the needs and abilities of the group members.

Comments and feedback from group members are collected routinely and additional notes made of ad hoc feedback. Client and caregiver expectations of the group and reactions to the group during and at its conclusion are recorded. Table 1 gives all the negative feedback ("What would we change") and a representative sample of positive written and verbal feedback.

The composition of the five groups run to date is shown in Table 2. Mixes of age, gender and diagnosis have been found within all five groups. Members also varied in whether they had received the dementia medication. These factors did not influence inclusion in the group and members disclosed their diagnosis and details of their own situation at their discretion.

The first two groups were held on day service premises with later groups based at local community facilities with no affiliation to health or social care. The change of venue has proved a positive one for members and facilitators. Being on 'neutral' ground emphasises the self-steering nature of the group and that staff members are not 'in charge'. The community venues used have been more easily accessible by foot or public transport for those who do not have their own transport. The ongoing group has been able to continue at a community site to create continuity and familiarity.

The change of venue has shown the flexibility of the Memory Group model, as have the variations in number and role of staff facilitating. Staff members facilitating the groups have included occupational therapists, psychologists, Age Concern employees, support workers and nursing staff. The number of facilitators has varied between 2-4. The variations across and within the five groups illustrate the applicability of the model. Its success is not the product of one lone dynamic individual, it is the outcome of collaboration between services, and it places value on user experience and emphasises the importance of support and psychosocial wellbeing. 
Table 1. Client and caregiver expectations of the group and reactions to the group during and at its conclusion

\begin{tabular}{|c|c|c|c|}
\hline What did we want? & What did we do? & What did we gain? & What would we change? \\
\hline Memory games & -Quizzes, games & $\begin{array}{l}\text {-'That we do not } \\
\text { have to go it alone' }\end{array}$ & -'Too short a term' \\
\hline $\begin{array}{l}\text { Opportunity to talk } \\
\text { to each other, }\end{array}$ & -Recited poetry & $\begin{array}{l}\text {-'We have been able } \\
\text { to talk to each other } \\
\text { get and give ideas } \\
\text { of how to deal with } \\
\text { problems' }\end{array}$ & $\begin{array}{l}\text {-'Never had anything } \\
\text { like this before... } \\
\text { more of the same please' }\end{array}$ \\
\hline Share experiences & $\begin{array}{l}\text {-'Looked at other } \\
\text { people's hobbies } \\
\text { and been inspired } \\
\text { by them, e.g. } \\
\text { photography, } \\
\text { scrapbooks' }\end{array}$ & & \\
\hline $\begin{array}{l}\text {-Meet people in a } \\
\text { similar situation who } \\
\text { may understand }\end{array}$ & & $\begin{array}{l}\text {-Learnt to keep one's } \\
\text { at times is essential' } \\
\text { patience although } \\
\text { not easy }\end{array}$ & -'Why does it have to end \\
\hline $\begin{array}{l}\text {-'Know you are } \\
\text { not alone' }\end{array}$ & $\begin{array}{l}\text {-Used the computer } \\
\text { to send emails and } \\
\text { make cards }\end{array}$ & & \\
\hline $\begin{array}{l}\text {-'Make our brains } \\
\text { work...I'm not } \\
\text { giving up' }\end{array}$ & $\begin{array}{l}\text {-Identifying film } \\
\text { stars from picture } \\
\text { cards }\end{array}$ & $\begin{array}{l}\text { 'We can learn } \\
\text { from others' }\end{array}$ & \\
\hline $\begin{array}{l}\text {-Opportunity to } \\
\text { 'offload' }\end{array}$ & $\begin{array}{l}\text {-Had discussions } \\
\text { many subjects: } \\
\text { on medical, driving, } \\
\text { legal, the news }\end{array}$ & $\begin{array}{l}\text {-Remember we all } \\
\text { need space, use it } \\
\text { when available' }\end{array}$ & \\
\hline Sharing & -Age and ageing & & \\
\hline $\begin{array}{l}\text { 'Getting out of } \\
\text { our shell' }\end{array}$ & & & \\
\hline
\end{tabular}

Table 2. Number of members and dropout rates across the five groups

\begin{tabular}{ccccc}
\hline $\begin{array}{c}\text { Group } \\
\text { Number }\end{array}$ & $\begin{array}{c}\text { Number of } \\
\text { Clients }\end{array}$ & $\begin{array}{c}\text { Number of } \\
\text { Guests }\end{array}$ & $\begin{array}{c}\text { Number of } \\
\text { facilitators }\end{array}$ & $\begin{array}{c}\text { Drop } \\
\text { out }\end{array}$ \\
\hline One & 4 & 4 & $2-4$ & 0 \\
Two & 5 & 5 & 4 & 1 \\
Three & 7 & 4 & 4 & 1 \\
Four & 3 & 3 & 2 & 0 \\
Five & 4 & 4 & 3 & 2 \\
\hline
\end{tabular}


The very small number of people who have attended the group and then failed to return also shows the success of the model. There have been only four dropouts across the five groups and the reasons are outlined in Table 3. Dropout was minimal and typically related to external circumstances such as change in work or transport arrangements. Several younger male clients attended on their own as their partners worked or they were single. However for these same reasons some declined to attend the group. The time and day of each of the five groups has varied to increase accessibility.

\section{Table 3. Drop out rates and reasons}

\begin{tabular}{lll}
\hline Group Number & Drop out & Reason given \\
\hline Two & $\begin{array}{l}1 \text { guest (attended one } \\
\text { early session, did attend } \\
\text { a later reunion session) }\end{array}$ & $\begin{array}{l}\text { This woman said she liked } \\
\text { to use the time for her } \\
\text { self while her husband } \\
\text { was at the group }\end{array}$ \\
Three & 1 male member & $\begin{array}{l}\text { Younger man who } \\
\text { attended alone } \\
\text { as partner worked. }\end{array}$ \\
Five & 1 client and son & $\begin{array}{l}\text { Son was unable to } \\
\text { get the time off work }\end{array}$ \\
\hline
\end{tabular}

Feedback from members of the group, facilitators and related healthcare services has been collated throughout the duration of the five groups. The informal feedback given throughout the groups has been useful in adapting the group's structure and content. Several significant changes have arisen as a result; the duration of the group has been extended from 8 to 10 weeks following member feedback. An ongoing fortnightly group was also established following comments that the group was not long enough 'great...too short a time...more of the same please' (client comment).

\section{Client feedback}

Several wellbeing indicators (Bradford Dementia Group cited in Perrin \& May, 2000) are evident in client feedback including social contact, expressing appropriate emotions, and responding appropriately to others. 'It's good to know you're not the only one.... An opportunity to meet people with the same problems.... Don't get a chance to talk like this anywhere else'

Further wellbeing is indicated by creative self-expression during activities, humour and self-respect. 'We could relax and say what we wanted to, not like sometimes when you can't get out what you want.... It's good to know you're not the only one...an opportunity to meet people with the same problems...'

From the collated member feedback there has been an extension of the duration of the Memory Groups from 8 to 10 weeks. The evaluative comments have also led to the establishment of an ongoing fortnightly group, open to any previous group member.

\section{Caregiver/guest feedback}

Further valuable feedback has been provided by the caregivers/guests who attend the groups. The five groups have seen a variety of partners, spouses, children and support workers attend as guests. Their feedback has highlighted the value of attending together while having the opportunity to mix with others. The chance to ask questions in a safe environment and to begin to challenge prior perceptions: 
$\therefore . . . A$ very good innovation, most instructive and wonderful support...mum is more confident and happier about her forgetfulness now that she has mixed and talked to others suffering from dementia... I don't feel as guilty now when I try to help her be more organized and independent...you don't like to discuss things with family and friends; they have enough problems of their own.' (Caregiver comment).

With the support and experiential knowledge shared by other members, caregivers have gained support and information as they work on acceptance and coping:

'...an opportunityto share and learn about the difficulties experienced from day to day' (Facilitator feedback).

Facilitators keep journals after each session to reflect on the session content and future learning points, noting any comments or ideas for improvement. A review of the journals has shown key strengths of the groups.

Activities provide an opportunity for conversation, company, fun and laughter. It may allow the person with dementia to feel busy or useful, to feel a part of the group. Activities engage members' senses and stimulate their mind and body. 'Most times content is led by the group, they work hard and support each other...you can see the pleasure...' (Occupational Therapist)

'The group has been a learning experience for everyone involved. We are all equal members of the group and at different times various members may take a lead...the larger group often split into splinter groups during activities allowing for more personal conversations and support; this was often a time for the caregivers to share coping strategies and express concerns to peers or facilitators' (Facilitator comment).

'...I feel privileged to have been present when people have expressed both their fears and their insights with courage and strong emotion, and also to have experienced the empathic bonds created between the group members' (Assistant Psychologist).

The group has taken a strengths-based approach (Knocker, 2002) creating a more positive and optimistic picture of the current situation. There are many roles that are often abandoned or taken away from a person with dementia when they are still achievable. This focus on strengths and maintaining relationships by attending together '...allows acknowledgement of any difficulties but focuses on abilities and interests' (Facilitator comment).

\section{Other healthcare professionals}

Feedback from related service professionals has proved valuable in moving to establish continued provision for this client group. The Memory Assessment and Therapy Service team are the main source of referrals. They are often the first to suggest and discuss the group with clients and caregivers.

'The Memory group is a place for support and understanding where no explanations are needed' (Memory Assessment and Therapy Service CPN)

'...An opportunity to join others on the same journey as yourself...no questions, no criticism, just love and support' (Memory Assessment and Therapy Service CPN)

'Via the facility of the ten-week Memory Groups people with dementia and their caregivers are given a unique opportunity to explore personal and inter-relationship issues in a positive and supportive environment' (Assistant Psychologist) 


\section{Conclusions and recommendations:}

The Calderdale Memory Group:

- Is the outcome of collaboration between services

- Places value on user experience and is flexible to needs

- Emphasises the importance of psychosocial wellbeing and the potential exacerbation of presentation created by 'illbeing' (Bradford Dementia Group)

- Provides support, activity and information tailored to the individual -focus on abilities and strengths not losses

- Promotes services for client and caregiver together- aiming to strengthen and maintain relationships

Recommendations for other sites adopting this model:

- Be flexible to member needs

- Ongoing evaluation is essential

- The venue is important: consider accessibility and the connotations of the site (e.g., affiliated to the health service versus community venue)

- Establish ground rules in the first session (e.g., give others time to speak, listen, keep to time, etc)

- Consider the mix of people in the group, particularly the stage of dementia. Consider the interactions between members

- Let members lead the sessions

- Encourage patience and support carers in allowing clients to retain valuable roles while they are still achievable

- Take time for facilitators to debrief after each session

\section{Acknowledgements:}

Thank you to Sarah McCormack for her continued support. Thanks also go to Professor Chris Leach, the members of the Calderdale Memory Groups, and all those involved in supporting its continuation. 


\section{References}

Alzheimer's Society (2005).

http://www.alzheimers.org.uk/Facts_about_dementia/. Retrieved August 2005.

Bender, M., \& Constance, G. 2005. Wade Bridge Memory Bank: a psycho education group, parts I \& II. Journal of Dementia Care 13, 19-21.

Clare, L. 1999. Memory rehabilitation in early dementia. Journal of dementia care 7, 33-38.

Davidson, L., Chinman, M., Moos, B., Weingarten, R., Stayner, D.A., \& Tobos, J.K. 1999. Peer support among individuals with severe mental illness: A review of the evidence. Clinical Psychology: Science and Practice 6, 165-187.

Harris, D. 2003. Helping to cope with forgetfulness. Unpublished guide for clients. Cited in Robinson, L. 2003. A case study of the psychological treatment of a woman in the early stages of a dementia with anxiety. PSIGE Newsletter 82, 29-37.

Kaufman, C.L., Freund, P.D., \& Wilson, J. 1989. Self-help in the mental health system: A model for consumer-provider collaboration. Psychosocial Rehabilitation Journal 13, 520-531.

Kitwood, T. 1997. Dementia Reconsidered. Maidenhead: Open University Press. Knocker, S. 2002. The Alzheimer's Society book of activities. London: Alzheimer's Society.

Marshall, A. 1999. A Study of day hospital use and follow-up in older adults with functional mental health disorders. In MacLean-Steel, K. \& Palmer, C. 1999. Improving the Care of Elderly People with Mental Health Problems: Clinical Audit project Examples. London: Gaskell.

Marshall, A. 2001. Coping in early dementia: findings of a new type of support group. University of Surrey: Unpublished PsychD. Thesis.

Marshall, A. 2003. Peer support among clients: an underused resource. Clinical Psychology 26, 11-14.

Nolan, M.R, Grant, G., and Ellis, N.C. 1990. Stress is in the eye of the beholder: reconceptualising the measurement of carer burden. Journal of Advanced Nursing $18,759-66$.

Nolan, M.R, Grant, G., and Keady, J. 1996. Understanding family care. Buckingham and Philadelphia: Open University Press.

Perrin, T. \& May, H. 2000. Wellbeing in Dementia: An occupational approach for therapists and carers. London: Churchill Livingstone.

Royal College of Psychiatrists 2005.

http://www.rcpsych.ac.uk/info/factsheets/pfacTreatAlz.asp. Retrieved August 2005.

Solomon, P. 2004. Peer support/Peer provided services underlying processes, benefits and critical ingredients. Psychiatric Rehabilitation Journal 27, 329-402.

Yale, R. 1995a. Hope and help in the early stages of Alzheimer's disease. Unpublished.

Yale, R. 1995b. Developing support groups for individuals with early-stage Alzheimer's disease: Planning, implementation and evaluation. Baltimore, Maryland: Health Profession Press. 
